\title{
Conceptual Design of a Single-Aisle Turboelectric Commercial Transport with Fuselage Boundary Layer Ingestion
}

\author{
Jason R. Welstead* \\ NASA Langley Research Center, Hampton, VA 23681, United States of America \\ and James L. Felder ${ }^{\dagger}$ \\ NASA Glenn Research Center, Cleveland, $\mathrm{OH}$ 44145, United States of America
}

\begin{abstract}
A single-aisle commercial transport concept with a turboelectric propulsion system architecture was developed assuming entry into service in 2035 and compared to a similar technology conventional configuration. The turboelectric architecture consisted of two underwing turbofans with generators extracting power from the fan shaft and sending it to a rear fuselage, axisymmetric, boundary layer ingesting fan. Results indicate that the turboelectric concept has an economic mission fuel burn reduction of $7 \%$, and a design mission fuel burn reduction of $12 \%$ compared to the conventional configuration. An exploration of the design space was performed to better understand how the turboelectric architecture changes the design space, and system sensitivities were run to determine the sensitivity of thrust specific fuel consumption at top of climb and propulsion system weight to the motor power, fan pressure ratio, and electrical transmission efficiency of the aft boundary layer ingesting fan.
\end{abstract}

\section{Nomenclature}

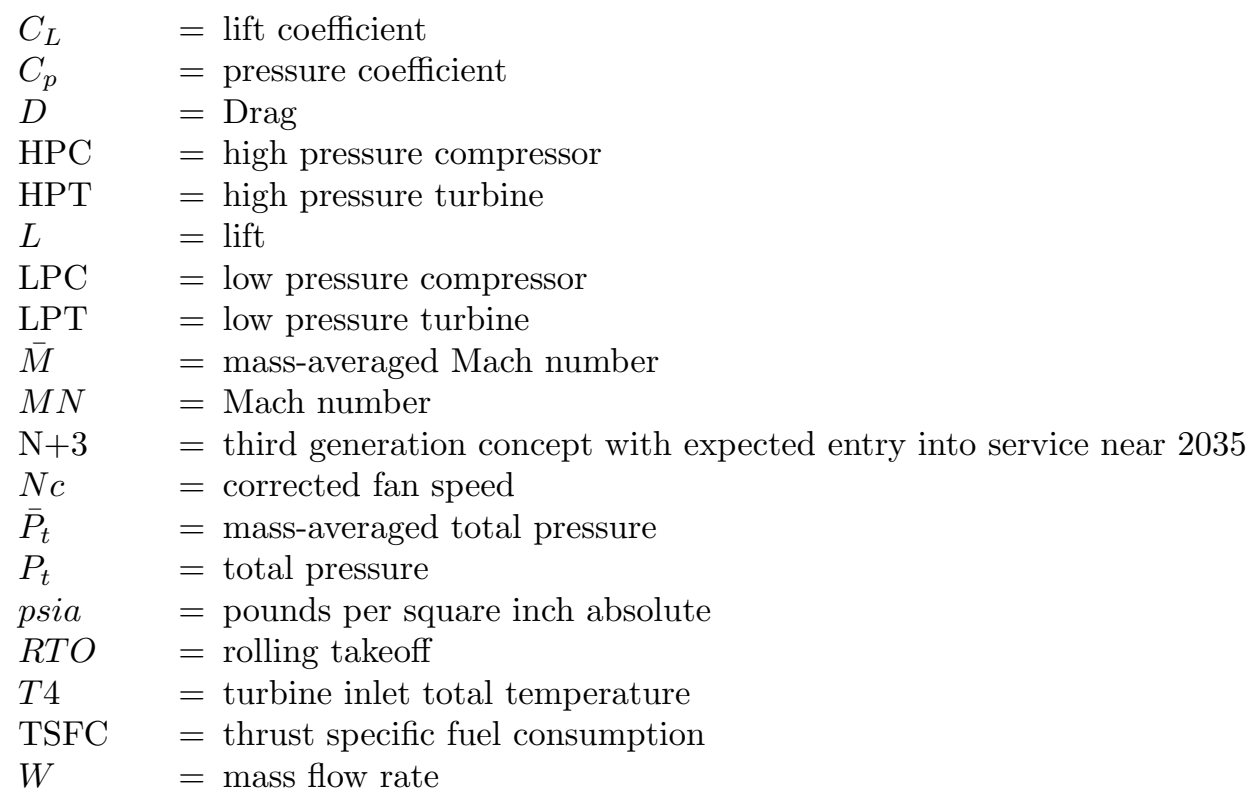

*Aerospace Engineer, ASAB, NASA Langley Research Center, 1 N Dryden St. M/S 442, Hampton, VA 23681, Member AIAA.

$\dagger$ Aerospace Engineer, LTA, NASA Glenn Research Center, 21000 Brookpark Rd, Cleveland, OH 44145 


\section{Introduction}

Merging technologies are resulting in a potential paradigm shift in how future commercial transport Eaircraft are designed. The current production tube-and-wing aircraft with underwing engines have been the norm since the introduction of the Boeing 707 in the late 1950's, ${ }^{1}$ but with technology advancements in composites and electric components, such as batteries and motors, that trend is changing. NASA's Advanced Air Transport Technology (AATT) project, previously the Fixed-Wing project, and Subsonic Fixed Wing project prior to that, has the long term goal of drastically reducing fuel burn, emissions, and noise beyond the current yearly incremental improvements. Advanced, efficient electrical components with high power densities could lead to a bifurcation point where highly efficient design concepts divert from historical trends.

A technology that could lead to a drastic shift in aircraft design is the turboelectric propulsion architecture. In this architecture, hydrocarbon fuel-burning turbomachinery is coupled to a generator that distributes power to propulsors positioned to provide synergistic propulsion-airframe integration (PAI). All power comes from the fuel and is not provided by any on board energy storage devices, such as batteries. This turboelectric distributed propulsion (TeDP) architecture decouples the power producing components from the thrust producing components allowing the two to be widely separated, with each operating at peak efficiency conditions rather than a compromise between the two, increasing the overall thermal efficiency. This architecture opens the door for completely new system architectures never before possible.

A detrimental effect that must be modeled is the efficiency loss due to the power conversion from mechanical to electrical, transmission of electrical power, and the conversion from electrical power back to mechanical power. However, this system architecture enables technologies to help overcome the efficiency losses. Examples include distributed fans, which increases the effective bypass ratio while reducing fan pressure ratio (FPR), and boundary layer ingestion (BLI), which increases the overall vehicle efficiency through a propulsive efficiency increase and reduced vehicle wake dissipation.

A single-aisle turboelectric aircraft with an aft boundary layer propulsor (STARC-ABL) was developed as a possible concept that takes minimal advantage of the turboelectric architecture and the ability to distribute the power. The concept is a tube-and-wing configuration with two underwing mounted turbofans. Attached to each turbofan is a generator that extracts mechanical power from the fan shaft and converts it to electrical power. Electrical wires send it to a rear mounted boundary layer ingesting, electrically powered fan. The STARC-ABL concept was developed as a first look at the turboelectric propulsion architecture for a single-aisle class commercial transport, and to determine if a benefit exists for a mostly conventional configuration with moderate distribution of propulsion power, or if all the system benefits are lost due to electrical system losses and can only be overcome with a fully distributed propulsion system.

The STARC-ABL concept was sized for a mission similar to current day Boeing 737-800 or Airbus A320 configurations. The concept mission definition, performance requirements, and a description of the STARCABL concept are given in Section II, along with a relevant advanced technology tube-and-wing conventional concept similar to the Boeing Refined SUGAR (Subsonic Ultra Green Aircraft Research) concept. ${ }^{2-7}$ The turboelectric propulsion architecture and modeling is described in Section III. Finally, results and discussion follow in Section IV concerning the impact of the turboelectric architecture on the design space and an exploration of system sensitivities.

\section{Concept Descriptions and Modeling}

Two single-aisle commercial transport concepts were developed assuming an entry into service in the 2035 timeframe $(\mathrm{N}+3)$, a baseline $\mathrm{N}+3$ conventional configuration $(\mathrm{N} 3 \mathrm{CC})$ and a turboelectric concept (STARC$\mathrm{ABL}$ ). Both concepts utilized technologies that were assumed to be at technology readiness level $\left(\mathrm{TRL}^{8}\right) 6$ by the year 2025, mission profiles that use advanced air traffic management, and were similar in wing-body configuration with two underwing propulsors. Key differences between the concepts were the turboelectric architecture, the rear fuselage BLI fan employed by the STARC-ABL concept, and the T-tail empennage resulting from the rear fuselage fan placement. Having the greatest commonality between the concepts was determined to be the best way to evaluate the impact of the turboelectric propulsion system architecture with a rear fuselage BLI fan. 


\section{A. Mission Definition and Performance Requirements}

The mission definition and performance requirements for the STARC-ABL and N3CC were based upon the Refined SUGAR concept developed by Boeing. ${ }^{2,3}$ As a concept similar in passenger count and technology assumptions, the Refined SUGAR was a natural choice in selecting comparable performance requirements and a reference mission.

The mission used to size the baseline configuration and the turboelectric concept assumes advancements in air traffic management that allow for more optimized flight trajectories with less time spent performing ground operations. The mission profile shown in Fig. 1 was created to provide a mission similar to the Refined SUGAR N+3 mission profile. ${ }^{3}$ The mission profile had an optimized climb segment not subject to airspeed constraints, a cruise climb segment that allowed the vehicle to fly at the optimal altitude for specific range, and an optimized descent. Taxi in and taxi out operations time were reduced to 4 minutes. The reserve mission was also modified to account for future operations. The flight fuel allowance was dropped from $5 \%$ to $3 \%$, and the hold time was reduced from 30 minutes to 10 minutes. The $200 \mathrm{~nm}$ alternate airport distance remained unchanged.

The design mission for both the N3CC and STARC-ABL concepts was 3,500 nm at a fixed-cruise Mach of 0.70 operating at an optimal altitude to maximize specific range. While 3,500 nautical miles was the required design mission range, the configurations were sized to minimize the economic mission $(900 \mathrm{~nm})$ block fuel. The takeoff field length requirement was less than 8,190 feet, a distance calculated as the greater of the balanced field length or $115 \%$ of the field length to clear a 35 foot obstacle with all engines operating. This takeoff field length requirement was matched to the Refined SUGAR requirement. ${ }^{3}$ The propulsion system was required to have sufficient thrust to meet the second segment climb and missed approach gradients in the event of a single engine failure, and have adequate thrust to meet the initial cruise altitude capability (ICAC) requirement, meaning that the vehicle was capable of climbing higher than the optimal starting cruise altitude subject to a 300 foot per minute minimum rate of climb requirement. The landing field length requirement was the same as the takeoff field length $(8,190 \mathrm{ft})$, and the approach velocity was limited to 140 knots.

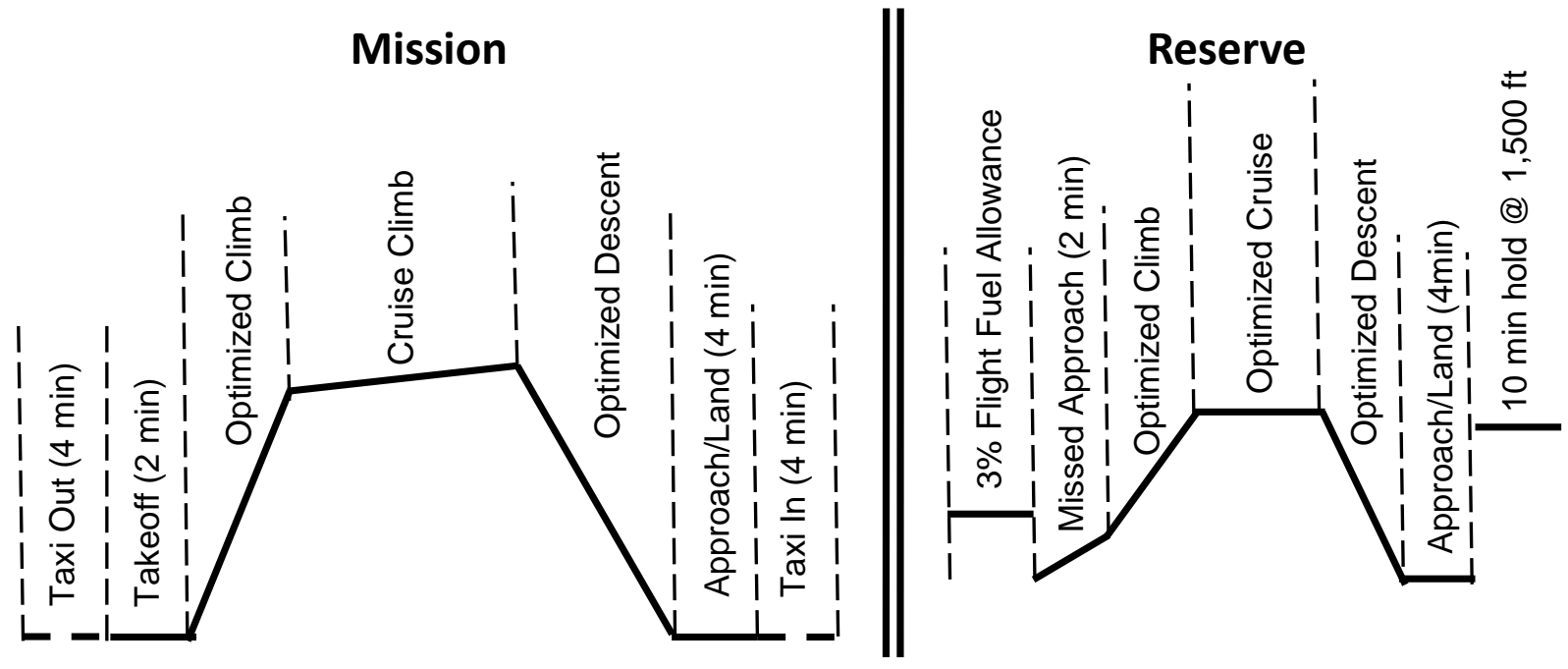

Figure 1: Mission profile for $\mathrm{N}+3$ concepts as modeled in FLOPS.

\section{B. N+3 Conventional Configuration (N3CC) Baseline}

A model similar to the Boeing Refined SUGAR was developed using in-house tools including Open Vehicle Sketch Pad (OpenVSP) ${ }^{9,10}$ for modeling the geometry and calculating wetted areas, a horizontal and vertical tail sizing routine based upon wing and fuselage geometry, ${ }^{11}$ and the Flight Optimization System (FLOPS) for mission analysis and performance. ${ }^{12}$ The Refined SUGAR-like model was developed using data from Refs. 2-7, and had an engine model developed by Georgia Tech based upon the gFan+. High level data for the gFan+ is described in Ref. 6. The Refined SUGAR was a single-aisle advanced tube-and-wing concept designed to carry 154 passengers in a two class seating arrangement, cruise at Mach 0.70 with a range of 
$3,500 \mathrm{~nm}$, and an overall geometry similar to the current day 737-800. The Refined SUGAR concept was designed for entry into services (EIS) in the 2035 timeframe and had numerous advanced technologies to reduce fuel burn, noise, and emissions. Advanced technologies included fuselage riblets for reduced viscous drag, advanced airfoils with laminar flow, a moderately high aspect ratio wing as the Refined SUGAR was span constrained to the current 737-800 span, advanced composite materials, and NextGen air traffic management (ATM) allowing optimized flight profiles. A complete list of technologies can be found in Ref. 2.

A complete, self-consistent dataset was not available for the Refined SUGAR as the concept evolved throughout the development. As such, a model was pieced together using published data, and any unknown parameters were filled with assumed values and then tweaked to help tune the model to the published data.

The aircraft geometry was modeled in OpenVSP and FLOPS using data tables and the three-view drawing from the SUGAR Phase I final report. ${ }^{3}$ Any unknown geometry inputs were estimated using values from an in-house 737-800like FLOPS model. FLOPS internal weight estimation routines were used to calculate an initial component weight for all the subsystems, and then calibration factors were used to tune the FLOPS component weights to the SUGAR Phase I "as-drawn" weight statement. ${ }^{2,3}$ The aerodynamics were estimated using FLOPS internal routine originally based upon the Empirical Drag Technique (EDET). ${ }^{13}$ Aerodynamic data for a single condition was available for the "as-drawn" Phase I design at Mach 0.74, an altitude of 38,408 feet, and a lift coefficient of 0.675 . Technology factors were included in the FLOPS aerodynamics inputs to account for the $7 \%$ fuselage drag reduction due to riblets, and $50 \%$ laminar flow on the upper surface of the wing.

The original engine model used in the Refined SUGAR-like model was based upon the gFan+ engine and developed at Georgia Tech, but the full lineage of the engine model was unknown. To alleviate this uncertainty in the engine model and to use a consistent engine model between the conventional configuration and the turboelectric configuration, an N+3 engine model was developed in the Numerical Propulsion System Simulation (NPSS) a using publicly available data to provide similar performance to the gFan + . Using the same engine model for both concepts eliminates discrepancies in system performance resulting from differing engine models, while eliminating the uncertainty in the model lineage. The $\mathrm{N}+3$ engine model will be described in greater detail in Section III. With a new engine model, the baseline configuration was sized by varying wing area and sea level static (SLS) thrust, becoming the N+3 Conventional Configuration (N3CC). A comparison of the Refined SUGAR concept data to the NASA Refined SUGAR-like and N3CC models is given in Table 1.

Table 1: Comparison of the sized $\mathrm{N}+3$ conventional configuration to published data.

\begin{tabular}{lcccc}
\hline \hline Parameter & Units & $\begin{array}{c}\text { Refined } \\
\text { SUGAR }^{5}\end{array}$ & $\begin{array}{c}\text { NASA Refined } \\
\text { SUGAR-like }\end{array}$ & $\begin{array}{c}\text { N+3 Conventional } \\
\text { Configuration }\end{array}$ \\
\hline TOGW & $\mathrm{lb}$ & 132,100 & 132,630 & 129,260 \\
OEW & $\mathrm{lb}$ & 75,300 & 76,000 & 73,690 \\
Wing Area & $\mathrm{ft}^{2}$ & 1,420 & 1,390 & 1,220 \\
Thrust (total, SLS) & $\mathrm{lb}$ & 38,600 & 37,680 & 41,020 \\
Optimal C $L$ & - & 0.595 & 0.66 & 0.59 \\
L/D @ Opt. C & - & 22.3 & 22.1 & 21.3 \\
Mid Cruise TSFC & $\mathrm{lb} / \mathrm{hr} / \mathrm{lb}$ & 0.451 & 0.452 & 0.438 \\
900 nm Block Fuel/Seat & $\mathrm{lb} /$ seat & 42.34 & 41.72 & 39.53 \\
\hline
\end{tabular}

\section{STARC-ABL Concept}

The STARC-ABL concept was derived from the N3CC configuration with key differences being the turboelectric propulsion architecture coupled with resized turbofans to meet system thrust requirements, an axisymmetric rear fuselage BLI fan (aft-fan), a T-tail to accommodate the aft-fan, and a resized wing to meet the mission and performance requirements. Figure 2 shows the STARC-ABL concept as modeled in the parametric geometry tool, OpenVSP. Wing area and thrust were varied to size the STARC-ABL concept, subject to the performance requirement discussed previously, with minimizing economic block fuel

${ }^{a}$ http://www.swri.org/npss/default.htm 
burn being the objective for the Design Explorer optimizer in ModelCenter ${ }^{\circledR \mathrm{b}}$, a multidisciplinary analysis framework.

The STARC-ABL concept utilizes the turboelectric propulsion architecture in a minimalist way; only partial distribution of power was utilized in the concept with the twin turbofans still providing a significant amount of thrust, $80 \%$ during takeoff and $55 \%$ at the top of climb (TOC) condition. The turboelectric architecture enables the decoupling of the power producing elements from the thrust producing elements giving the potential for distribution of the propulsors. This concept allowed for the implementation of the turboelectric architecture without the added system complexity of a fully distributed propulsion system, which would include numerous additional electrical system components, motors, and fans. Instead, this simplified implementation of the turboelectric architecture in the STARC-ABL concept enabled a first glance analysis to determine if any performance benefits exist without fully distributed propulsion.

Several simplifying assumptions were made to elimi-

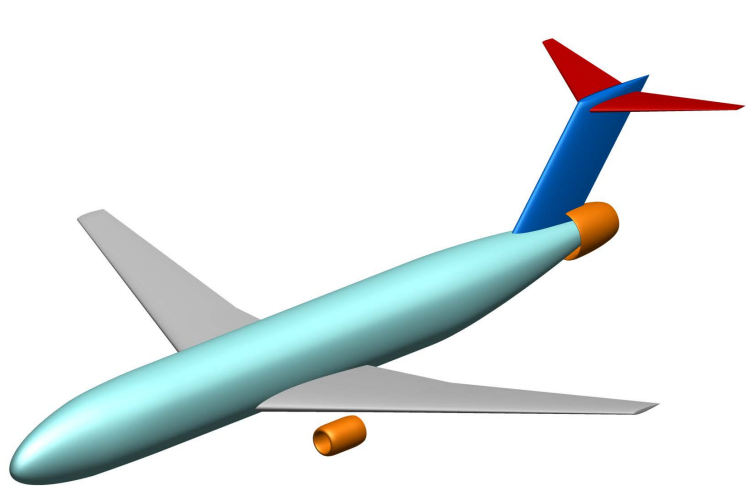

Figure 2: STARC-ABL isometric view as modeled in OpenVSP. Key features include the rear fuselage BLI fan, the T-tail empennage, and the reduced size turbofans allowed by the turboelectric propulsion system. nate the necessity for higher order tools that would drastically increase the analysis time. The emphasis of this effort was to take a first look at the concept to determine if any potential benefits exist using a turboelectric architecture with moderately distributed power. No detailed aerodynamic shaping of the rear fuselage and fuselage fan nacelle was performed. A nominal shape was developed in OpenVSP and the wetted areas were calculated for the viscous drag calculation in FLOPS. The surface area covered by the rear fuselage nacelle was subtracted from the surface area added by the external portion of the nacelle, resulting in a net wetted area increase. The surface area inside the nacelle was accounted for in the propulsion system model.

An important consideration for a turboelectric architecture is the thermal management and heat rejection systems as they reduce the system total efficiency. The losses due to the thermal management system (TMS) were ignored as there was no conceptual level way to estimate the thermal management system requirements. A rough order of magnitude weight estimate was included to capture the weight penalty based on the specific power $(\mathrm{kW}$ thermal $/ \mathrm{kg}$ ) of the TMS for a high power electrical system used in a "more electric" aircraft, but the power requirements of a thermal management system were not modeled. Modeling of the thermal management system would require significant tool development and was beyond the scope of this work.

A conventional electrical system was assumed to avoid dependence on a complex cryogenic cooling system to achieve any sort of system benefit. As such, a set of conservative component electrical efficiencies were chosen resulting in a total electrical system efficiency of $90 \%$, accounting for all the losses between the turbine generator and the aft-fan. The aft-fan was designed to operate at a constant 3500 horsepower at high throttle settings, and the motor horsepower was reduced at low throttle settings due to operational constraints of the low pressure compressor (LPC) in the turbofan core. This simplified throttling schedule for the aft-fan may not be the optimal throttling for this configuration, but the constant power setting was chosen to reduce the number of design variables in the propulsion architecture. A more complex throttling scheme may provide increased system benefits.

As mentioned previously, no higher-order tools such as computation fluid dynamics (CFD) were used in the analysis of the N3CC or STARC-ABL concepts. Given that the STARC-ABL concept has a rear fuselage BLI fan, a method for capturing the boundary layer effects without a viscous CFD analysis of the aircraft fuselage and tail cone, with the aft BLI fan included in the flow field, had to be developed. Two viscous CFD solutions for the aft region of a modified Boeing fuselage ${ }^{6}$ were readily available and were used to generate the boundary layer profiles, one at takeoff and one at top of climb. This boundary layer data was normalized in such a way as to allow it to be used at other flight conditions, giving an initial estimate of the boundary layer at different axial locations along the tail cone without further CFD analysis. This drastically simplified the analysis and allowed for rapid exploration of the design space, but implies that the accuracy of this analysis relies heavily upon the validity of the Boeing CFD solution. The CFD solution and

\footnotetext{
${ }^{b}$ http://www.phoenix-int.com/modelcenter/integrate.php
} 
boundary layer profiles are explained in greater detail in Section III.

\section{Propulsion System Architecture and Modeling}

The Georgia Tech implementation of the GE hFan engine ${ }^{7}$ was used for creating a model of the turboelectric propulsion system, and the turbofan component of the model was used in both the N3CC and STARC-ABL. This removed any potential modeling discrepancies and differing assumptions associated with two separate turbofan models. The hFan engine was used on the hybrid electric Boeing SUGAR Volt aircraft, and contained the same technology assumptions as the gFan+ (a model of which was also created by Georgia Tech). The Georgia Tech model of the hFan was modified to replace the motor with a generator. The aft-fan propulsor was located on the tail cone of the aircraft such that the nozzle exit plane extends slightly past the tip of the bare tail cone. Figure 3 shows the cross sections for the turbofan engine with generator (genFan) and the motor driven aft BLI propulsor (aft-fan). The cross section of the genFan was not redrawn and so serves only as illustration of a potential configuration. The aft-fan cross section was calculated by NPSS and WATE ++ (Weight Analysis of Turbine Engines) ${ }^{14}$ from the speeds, pressures, temperatures and flow rates obtained from the thermodynamic cycle of the aft-fan, also modeled by NPSS.

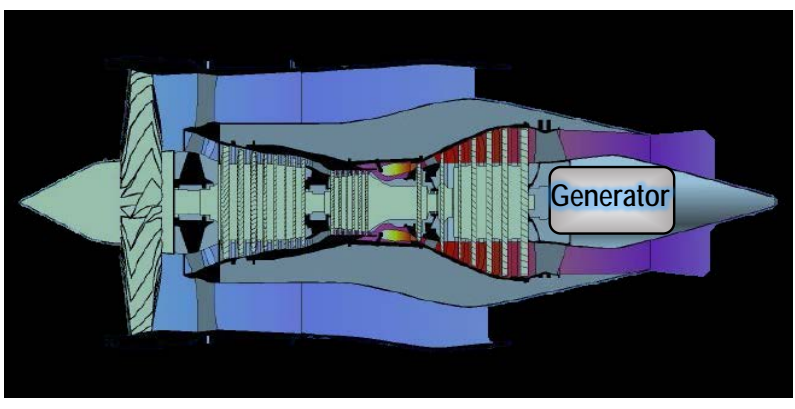

(a) Turbofan configuration with aft generator pulling power from the fan shaft.

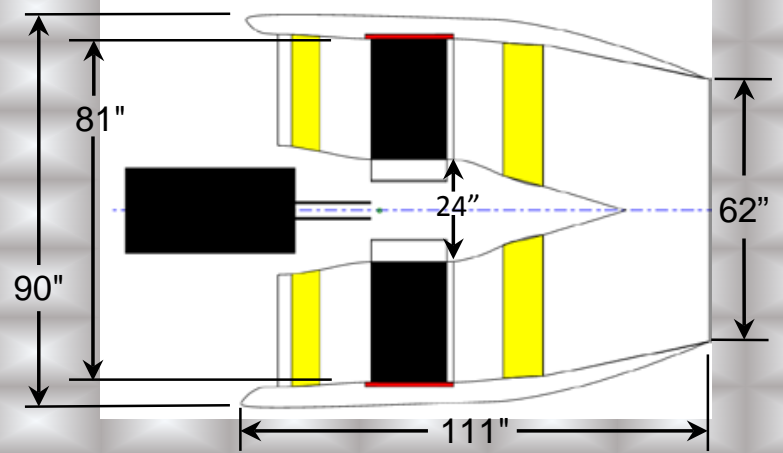

(b) Electric motor driven aft-fan located at the tip of the aircraft tail cone.

Figure 3: Conceptual drawings of the turbofan and rear fuselage propulsor for the turboelectric propulsion system.

The diameter of the inner surface of the flow passages in the aft-fan was set to equal the diameter of the bare tail cone of the baseline aircraft. The axial location of the inlet was determined by the computed length of the entire propulsor. This was critical because the flow conditions of the boundary layer vary with the axial location, especially as the flow nears the tip of the tail cone. As such the thermodynamic performance and the flow path computation were tightly coupled. The key design pressure ratios, temperatures, efficiencies, specific powers and specific weights for the genFan and aft-fan are listed in Table 2.

Table 2: Design assumption for the propulsion system architecture using assumptions based upon the public domain version of the Georgia Tech GE hFan. ${ }^{7}$

\begin{tabular}{lcc|lcc}
\hline \hline $\begin{array}{l}\text { Turbofan } \\
\text { Component }\end{array}$ & $\begin{array}{c}\text { Pressure Ratio or } \\
\text { Total Temperature }\end{array}$ & Efficiency & $\begin{array}{l}\text { Electrical/TMS } \\
\text { Component }\end{array}$ & $\begin{array}{c}\text { Specific Power or } \\
\text { Specific Weight }\end{array}$ & Efficiency \\
\hline Fan & 1.45 & $93.9 \%$ & Generator & $8 \mathrm{hp} / \mathrm{lb}$ & $96.0 \%$ \\
LPC & 1.45 & $92.0 \%$ & Motor & $8 \mathrm{hp} / \mathrm{lb}$ & $96.0 \%$ \\
$\mathrm{HPC}$ & 27.9 & $90.6 \%$ & Inverter & $10 \mathrm{hp} / \mathrm{lb}$ & $98.0 \%$ \\
$\mathrm{HPT}$ & $2800^{\circ} \mathrm{R}$ & $92.5 \%$ & Cable & $3.9 \mathrm{~kg} / \mathrm{m}$ & $99.6 \%$ \\
LPT & $1690{ }^{\circ} \mathrm{R}$ & $94.1 \%$ & Circuit Protection & $33 \mathrm{~kg} / \mathrm{MW}$ & - \\
Tail Cone Fan & 1.25 & $95.7 \%$ & TMS & $0.68 \mathrm{~kW} / \mathrm{kg}$ & - \\
\hline \hline
\end{tabular}

Central to the analysis of any boundary layer ingesting propulsion system is an accurate representation 
of the boundary layer velocity and total pressure profiles at the inlet of the BLI propulsion system. The flow regime in the tail cone region is especially complex due to the effects of diffusion of the airstream into the tail cone region being superimposed on the viscous boundary layer coming from the cylindrical section of the fuselage. This interaction makes it difficult if not impossible to determine an equivalent flat plate distance such that flat-plate boundary layer estimation methods can be used.

Fortunately, Boeing created a CFD model of the fuselage and tail cone for the SUGAR Freeze ${ }^{6}$ another of the SUGAR concept aircraft created as part of a NASA Research Announcement (NRA) study which also used a boundary layer ingesting aft-fan. Figure 4 shows the results of the CFD model superimposed on an image of the tail cone. The color contours on the surface of the tail cone represent the pressure coefficient $(\mathrm{Cp})$ of the flow at the surface of the tail cone. The color contours in the space above the tail cone surface represent the local Mach number. While difficult to see, the lines in the flow field represent constant velocity lines. The rapid spreading of these lines towards the tip of the tail cone is an indication of the degree to which the adverse pressure gradient of the diffusing flow in this region rapidly thickens the boundary layer. Boundary layer velocity and total pressure profiles at three different axial locations along the top and bottom centerline were extracted from the CFD solution set at sea level/Mach 0.2 and 42,000 ft/Mach 0.7.

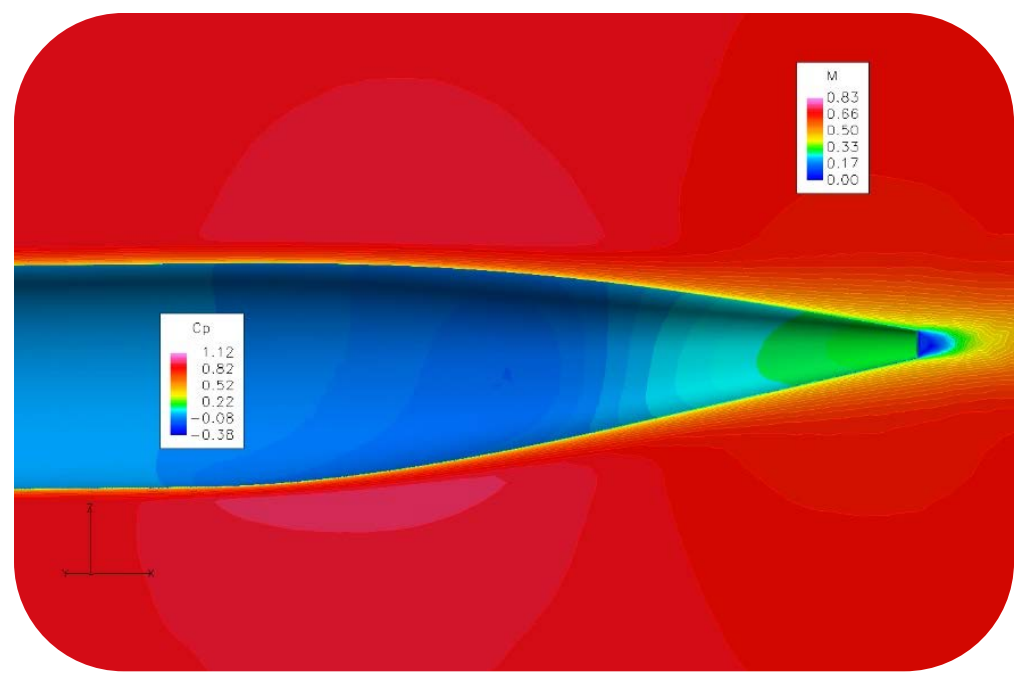

Figure 4: CFD solution of a rear fuselage reshaped for a ducted fan. ${ }^{6}$

Figure 5 contains the plots of the boundary layer velocity and total pressure as a function of height above the surface for 3 different axial locations. Of particular note is the approximately 50 inch height of the velocity deficit layer in the region near the tip of the tail cone. This height is much greater than would be the boundary layer height of a flat plate of the same length. Also of note is the relatively low loss of total pressure in this reduced velocity layer. The combination of these two details indicate that much of the momentum deficit in this layer is due to diffusion (which tends to preserve total pressure) rather than to viscous boundary layer losses (which tends to dissipate total pressure). The effect of a reduction in average inlet velocity is mainly seen in a reduction in inlet drag while the effect of a reduction in total pressure is mainly seen in a reduction in nozzle gross thrust. Thus a flow field such as seen here has the advantage of reducing inlet drag while not suffering as much loss in gross thrust as would be seen if the velocity deficit were due entirely to viscous losses.

A normalized representation or map of the boundary layer was prepared for use in the NPSS propulsion system model of the aft-fan. Several steps are used to produce this map. Equations 1 and 2 are used to calculate the mass-average Mach number $(\bar{M})$ and total pressure $\left(\bar{P}_{t}\right)$ for a given height within the boundary layer

$$
\begin{gathered}
\bar{M}=\frac{\sum_{i=0}^{x} M_{i} W_{i}}{\sum_{i=0}^{x} W_{i}} \\
\bar{P}_{t}=\frac{\sum_{i=0}^{x} P_{t_{i}} W_{i}}{\sum_{i=0}^{x} W_{i}}
\end{gathered}
$$

where $i$ is the $\mathrm{i}$-th layer between zero and a height $x$ in the boundary layer, and $M_{i}, P_{t_{i}}$, and $W_{i}$ are the Mach number, total pressure and mass flow rate in the i-th layer. The integrated value of the mass-averaged Mach number and total pressure is calculated for each height in the boundary layer. The mass-averaged values are normalized by the freestream Mach number and total pressure so that they can be used at different flight conditions.

The dimensioned height value in the boundary layer is also normalized by the full height value of the boundary layer. The height of the boundary layer is assumed to vary with only Mach number, so an estimate of the height at any Mach number can be obtained by interpolating between the two known heights at the two given Mach numbers. By normalizing both the $x$ and $y$ values of the boundary layer map, it is possible 


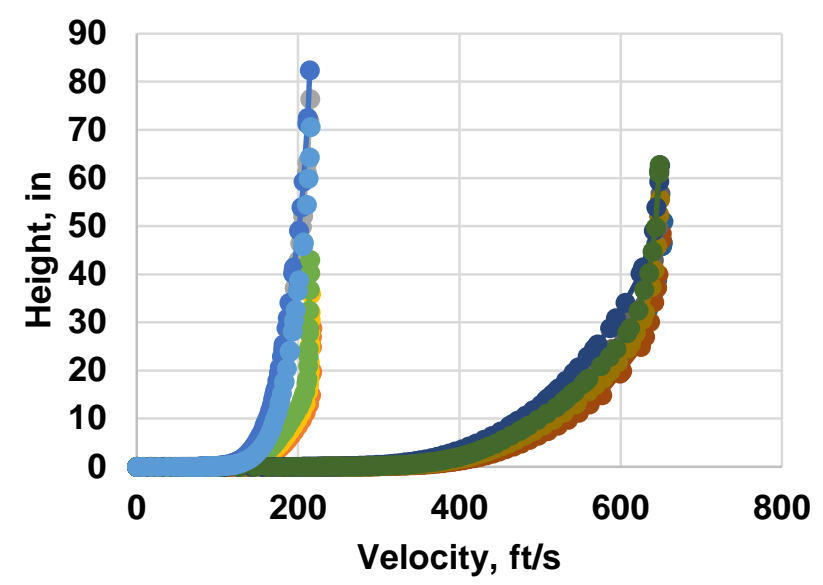

(a) Boundary layer velocity profiles.

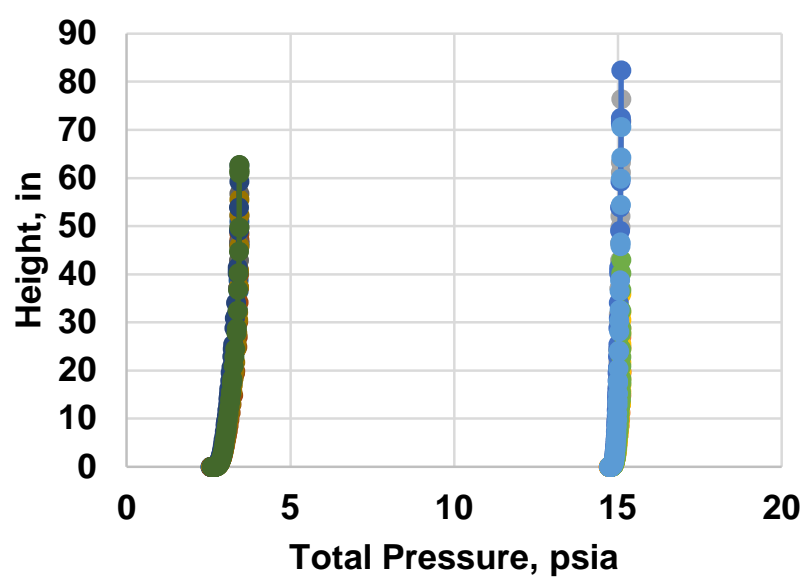

(b) Boundary layer total pressure profiles.

Figure 5: Top of climb and rolling takeoff boundary layer profiles from aft fuselage CFD solution of the Boeing SUGAR Freeze concept shown in Fig. $4 .{ }^{4}$ Various colors represent different longitudinal locations of the boundary layer profile.

to interpolate between the fully normalized boundary layer shapes to get a normalized profile shape at a desired Mach number. The unnormalized boundary layer profile at flight conditions other than for the two for which the data is known is obtained by using the boundary layer height for the given flight Mach number (interpolated from a table of boundary layer height versus Mach number) and the flight Mach number and total pressure.

This same methodology can be used to expand the map to have normalized boundary layer curves as both a function of Mach number and altitude when data for more flight conditions is known. It can even be expanded to include the boundary layer shapes as a function of aft-fan power to reflect the suction effect of the aft-fan on the shape of the upstream flow field at different power levels. The ability to compactly represent a large amount of precalculated data allows a very complex propulsion/airframe interaction to be included in a zeroth order cycle model.

Figure 6 shows the normalized boundary layer profiles used to compute the average inlet Mach number

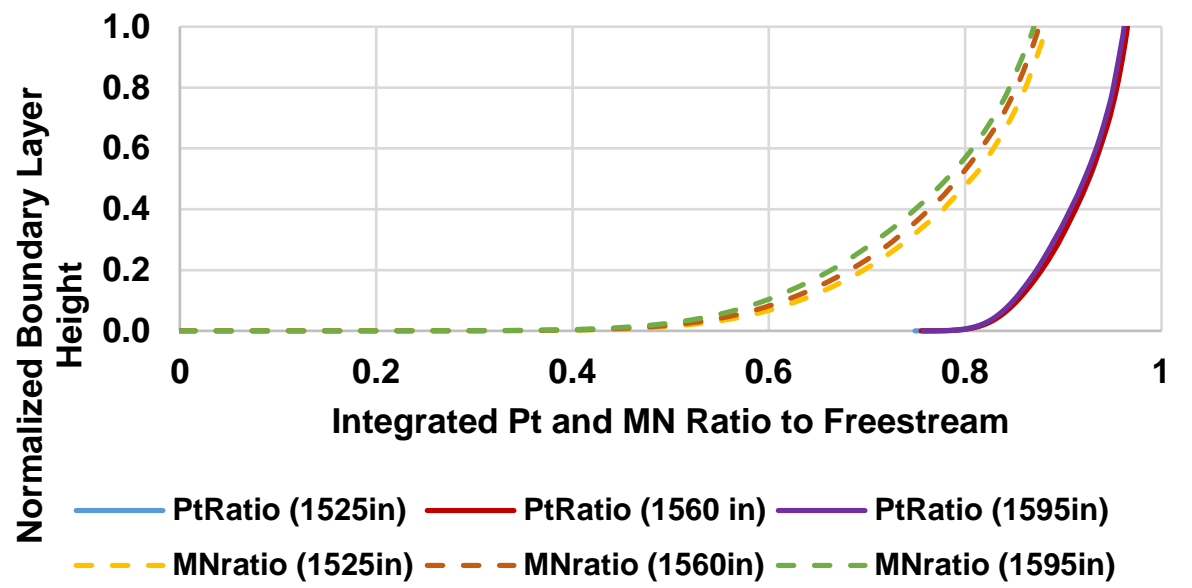

Figure 6: Ratio of total pressure and Mach number to freestream versus fraction of boundary layer captured for three different longitudinal fuselage locations.

and total pressure for a given capture height of the aft-fan. The individual lines are for the different axial locations on the tail cone. The velocity deficit in the region of the tail cone near the tip is driven more by diffusion rather than viscous drag. This can be seen from the greater spread in the mass averaged Mach number lines than in the total pressure lines since diffusion preserves total pressure while viscous losses, by 
definition, do not.

The difference between the average velocity for a given capture height in Fig. 6 and the freestream velocity represents the momentum deficit for the flow up to that height. As more of the boundary layer is captured, more of the total momentum deficit is captured. Figure 7 plots the fraction of the total momentum captured as a function of the fraction of the boundary layer captured. Since the velocity curve in the boundary layer follows a $(1 / 7)^{t h}$ order power curve, the momentum capture versus boundary layer capture curve is obviously very nonlinear. The result is that the momentum deficit in the bottom $10 \%$ of the boundary layer is much larger than in the top $10 \%$ of the boundary layer. From Fig. 7 it can be seen that capturing $20 \%$ of the boundary layer captures $40 \%$ of the total momentum deficit. Capturing an additional $20 \%$ of the boundary layer only captures an additional $25 \%$ of the momentum deficit.

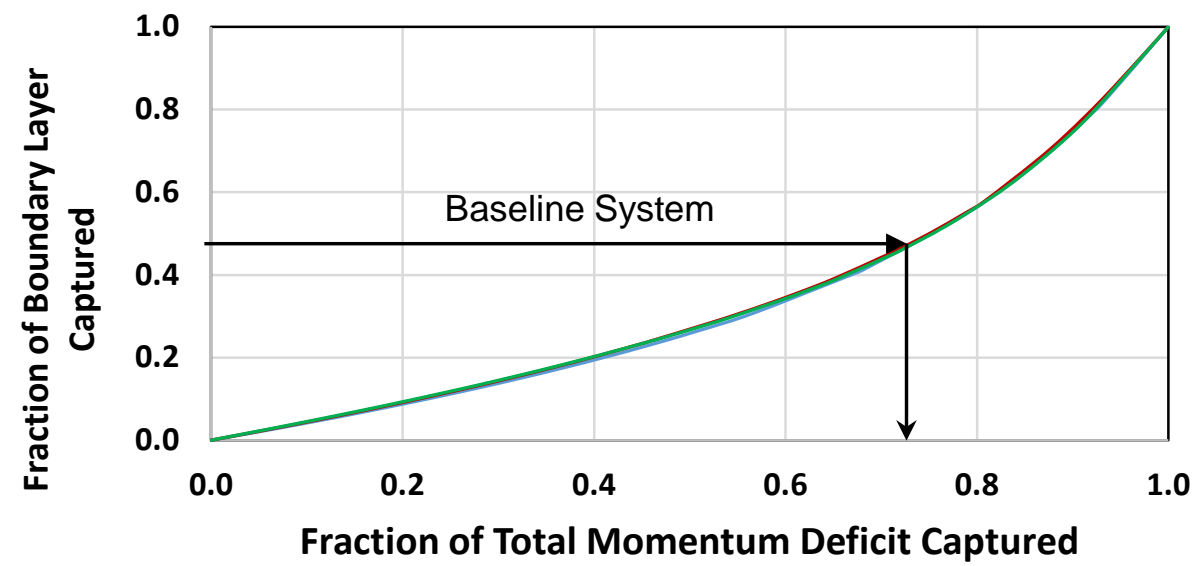

Figure 7: Fraction of momentum deficit captured by the rear BLI fan versus fraction of boundary layer captured. Arrows on graph show the baseline system with less than $50 \%$ of the boundary layer captured corresponds to over $70 \%$ of the momentum deficit captured.

For a given fan pressure ratio, the shaft power to the fan, and hence motor power, increases with increasing boundary layer capture. A power of 3500 horsepower was selected for this study as the maximum power that could be reasonably extracted from the turbofan engines. This amount of power was sufficient to capture $45 \%$ of the total boundary layer height. However, this was sufficient to capture $70 \%$ of the total momentum deficit. Capturing the entire boundary layer would require considerably more power, which might not be worth the extra weight and losses in the electrical system to capture, assuming that the turbofan engines could direct more power away from the fans and to the generators. In fact it is likely that there is an optimum fraction of the boundary layer to capture that is less than $100 \%$.

With a reasonable estimate of the boundary layer shape in hand, an NPSS model that contained both the underwing engines and the aft-fan was created. A summary of the resulting design is given in Table 3 and compared to the baseline turbofan performance. This model was sized to meet or exceed the thrust required by the aircraft at the top of climb (TOC) and rolling takeoff (RTO) flight condition. The TOC flight condition is $37,574 \mathrm{ft}$ at a Mach number of 0.7 and ISA standard day with total vehicle thrust required of $6797 \mathrm{lb}$. The RTO condition is sea level at a Mach number of 0.2153 and ISA hot day $\left(+27^{\circ} \mathrm{R}\right)$ with a total vehicle thrust required of $28,342 \mathrm{lb}$. The motor driving the aft-fan was assumed to have a continuous rated power of 3500 horsepower in the baseline configuration. The combination of all the individual component efficiencies in the electrical power transmission system gives a fan turbine shaft to aft-fan shaft efficiency of $90.4 \%$. As a result, the generator size was set at 1935 horsepower each or 3870 horsepower total. The total propulsion system was sized at the TOC condition such that the aft-fan was running at $100 \%$ corrected speed at input power of 3500 horsepower. The underwing generator turbofans (genFans) were then sized to provide the remaining thrust required while also driving the generators. The result is that thrust from the individual genFan is only $2030 \mathrm{lb}$ at TOC as compared to the $3400 \mathrm{lb}$ required of each baseline turbofan on the N3CC. Thus, the diameter of the fan as well as nacelle of the genFans is smaller. However, the core airflow rate is not substantially different due to the need for the fan turbine to generate nearly the same total shaft power. The model was executed off-design to make sure that the required RTO thrust was met or exceeded. If the thrust produced at the RTO was less than the required value, the design thrust at the 
Table 3: Propulsion system performance for both the baseline and turboelectric systems. The thrust and horsepower values for the baseline and generator/turbofans are the total of both turbofans. Propulsion system thrust requirements for sizing were TOC thrust $=6,800 \mathrm{lb}$, and RTO thrust $=28,340 \mathrm{lb}$.

\begin{tabular}{|c|c|c|c|c|c|c|c|c|c|}
\hline & \multirow[b]{2}{*}{ units } & \multicolumn{2}{|c|}{$\begin{array}{l}\text { Baseline } \\
\text { Turbofans }\end{array}$} & \multicolumn{2}{|c|}{$\begin{array}{l}\text { Generator } \\
\text { Turbofans }\end{array}$} & \multicolumn{2}{|c|}{$\begin{array}{c}\text { BLI Tail Cone } \\
\text { Propulsor }\end{array}$} & \multicolumn{2}{|c|}{$\begin{array}{c}\text { STARC-ABL } \\
\text { System }\end{array}$} \\
\hline & & TOC & RTO & TOC & RTO & TOC & RTO & TOC & RTO \\
\hline Thrust & $\mathrm{lb}$ & 6,800 & 34,920 & 4,060 & 22,780 & 3,210 & 5,560 & 7,260 & 28,350 \\
\hline TSFC & $\mathrm{lb} / \mathrm{hr} / \mathrm{lb}$ & 0.4410 & 0.2922 & - & - & - & - & 0.3875 & 0.3032 \\
\hline Thrust/HP & $\mathrm{lb} / \mathrm{hp}$ & 0.64 & 0.99 & 0.60 & 0.86 & 0.92 & 1.60 & 0.72 & 0.96 \\
\hline OPR & - & 58.0 & 51.0 & 58.0 & 49.6 & 1.25 & 1.08 & - & - \\
\hline $\mathrm{BPR}$ & - & 11.3 & 11.9 & 6.4 & 6.9 & - & - & 14.4 & 13.3 \\
\hline FPR & - & 1.45 & 1.39 & 1.45 & 1.49 & 1.25 & 1.08 & - & - \\
\hline$\% \mathrm{Nc}$ & - & $100 \%$ & $93.2 \%$ & $100 \%$ & $100 \%$ & $100 \%$ & $62.1 \%$ & - & - \\
\hline LPT Power & hp & 5,960 & 19,490 & 4,940 & 14,840 & - & - & - & - \\
\hline Fan Power & hp & 5,320 & 17,705 & 3,005 & 12,900 & 3,500 & 3,500 & - & - \\
\hline Generator/Motor & hp & - & - & 3,870 & 3,870 & 3,500 & 3,500 & - & - \\
\hline
\end{tabular}

TOC point was increased until the RTO thrust was sufficient. For the 3500 horsepower baseline motor size, the thrust lapse rate of the total system is such that the RTO thrust is the more constraining and so the TOC design thrust had to be increased to $7260 \mathrm{lb}, 463 \mathrm{lb}$ more than the required thrust.

The power management scheme used to determine the maximum system thrust was to match the genFan to the design fan percent corrected speed with constraints on maximum turbine inlet temperature (T4) while the aft-fan was run at a constant 3500 horsepower, regardless of altitude or speed. Running the aft-fan at 3500 horsepower resulted in $100 \%$ corrected fan speed for the aft-fan at the TOC sizing point, but only $62 \%$ at the RTO point. This was because the power required to run the fan at a given corrected speed increased considerably as the altitude decreased and air density increased. To run the aft-fan at the same corrected speed at the RTO point as the TOC point would require a considerably larger and thus heavier electrical power system. However, as a result of operating the aft-fan at a constant shaft power, the percentage of the thrust from the genFans increased from about $56 \%$ of the total at the TOC point to $80 \%$ at the RTO points. This is likely why the RTO thrust ended up being the more constraining of the two required thrust values.

At part power the propulsion system was matched to a fraction of the genFan fan max power corrected speed and a percentage the aft-fan motor rated power. Due to the effects of boundary layer ingestion the amount of thrust per shaft hp is higher in the aft-fan than it is in the genFans, about $0.92 \mathrm{lb} / \mathrm{hp}$ versus 0.67 $\mathrm{lb} / \mathrm{hp}$. In order to keep as much of the part power thrust coming from the more efficient thrust source for as long as possible, the aft-fan motor power was maintained at the maximum while the thrust of the overall system was reduced. The limiting factor is that as the fuel flow is reduced in the genFans while the generator power remains constant, the low pressure compressor (LPC) is driven towards stall. Once a minimum LPC stall margin was reached, the power to the aft-fan was reduced in order to stay at that minimum stall margin.

Table 4 presents a summary of the size and weight of the baseline turbofan in the N3CC and the nonelectrical portions of the turboelectric aft BLI fan system in the STARC-ABL. Table 5 details the design assumptions for specific power, efficiency, and size for the electrical system of the STARC-ABL system, the resulting weights of the major components, and the total weight of the electrical system. Table 6 gives the total propulsion system weight. The most startling result is that the total system weight of the turboelectric system (two genFans, one aft BLI fan, electrical system and TMS) is actually less than the weight of the baseline turbofan system (two baseline turbofans). This is not as impossible as it might seem at first glance. While the electrical propulsion system adds $2930 \mathrm{lb}$ to the system and the non-electrical portions of the aft BLI fan add another $2070 \mathrm{lb}$ for a total of $5000 \mathrm{lb}$ not present in a conventional turbofan system, the combined weight of the two genFans without the generators is $8460 \mathrm{lb}$ less than the two base turbofans. This is due mostly to the fact that the size of the turbofan fans is reduced from 70 to 52 inches in diameter. Also the nacelle and thrust reverser for the genFans are smaller and lighter. The result is that the total system weight is $3460 \mathrm{lb}$ lighter. 
Table 4: Non-electric propulsion system component sizes and weights.

\begin{tabular}{lccc}
\hline \hline Component & Baseline Turbofan & Generator/Turbofan & BLI Propulsor \\
\hline Fan Diameter & $70 \mathrm{in}$ & $52 \mathrm{in}$ & $81 \mathrm{in}$ \\
Nacelle Max Diameter & $78 \mathrm{in}$ & $58 \mathrm{in}$ & $90 \mathrm{in}$ \\
Nacelle Length & $156 \mathrm{in}$ & $115 \mathrm{in}$ & $111 \mathrm{in}$ \\
Bare Engine Weight & $4,460 \mathrm{lb}$ & $2,510 \mathrm{lb}$ & $1,370 \mathrm{lb}$ \\
Nacelle Weight & $3,910 \mathrm{lb}$ & $1,630 \mathrm{lb}$ & $700 \mathrm{lb}$ \\
Total Pod Weight & $8,370 \mathrm{lb}$ & $4,140 \mathrm{lb}$ & $2,070 \mathrm{lb}$ \\
\hline
\end{tabular}

Table 5: Electric system sizing and weight estimates.

\begin{tabular}{lcccc}
\hline \hline Component & Assumption & Efficiency & Size & Weight \\
\hline Electric Motor & $8 \mathrm{hp} / \mathrm{lb}$ & $96.0 \%$ & $3,500 \mathrm{hp}$ & $440 \mathrm{lb}$ \\
Inverter & $10 \mathrm{hp} / \mathrm{lb}$ & $98.0 \%$ & $3,500 \mathrm{hp}$ & $350 \mathrm{lb}$ \\
Generator $(2)$ & $8 \mathrm{hp} / \mathrm{lb}$ & $96.0 \%$ & $2 @ 1,137 \mathrm{hp}$ & $480 \mathrm{lb}$ \\
Cable $\left(2 \times 93^{\prime}\right)$ & $3.85 \mathrm{~kg} / \mathrm{m}$ & $99.6 \%$ & $1.44 \mathrm{MW}$ & $480 \mathrm{lb}$ \\
& $750 \mathrm{~V} / 1926 \mathrm{amps}$ & & & \\
Circuit Protection & $0.5^{*}$ Cable Weight & - & - & $240 \mathrm{lb}$ \\
TMS & $0.68 \mathrm{~kW} / \mathrm{kg}$ & - & $279 \mathrm{~kW}$ & $910 \mathrm{lb}$ \\
Total System & - & - & - & $2,930 \mathrm{lb}$ \\
\hline
\end{tabular}

A much more detailed examination of the weight of the turbofan engines in the two systems will have to be done before it is known whether the total propulsion system weight is in fact less than the baseline turbofans and if so whether it is to this degree or not. A Georgia Tech correlation based weight estimation method was used to estimate the weight of both the baseline turbofan and the genFan turbofan. ${ }^{15}$ Future analysis will use the WATE $++{ }^{14}$ detailed weight and flow path estimating tools built into NPSS to give a more analytical estimate of the STARC-ABL propulsion system weight as well as the baseline turbofan system weight. Regardless, however, of whether the total system weight is indeed over $3000 \mathrm{lb}$ lighter, is roughly the same, or is actually heavier than the baseline turbofan system, the primary takeaway is that the aft BLI fan system is not simply adding weight to the baseline turbofan. There are parts of the propulsion system which become lighter as a result of adding an aft BLI fan to the propulsion system. The final system weight will then depend on the balance between the changes that add weight to the system with those that remove weight from the system. What is certain is that the final system weight will be less than what it would be if the electrical system and the aft BLI fan were simply added to the baseline turbofan weight.

The above analysis is based on both propulsion systems being designed to the same thrust requirements. When the vehicle is re-optimized around the lower fuel weight that results from the better fuel efficiency of the aft BLI fan propulsion system, the takeoff gross weight (TOGW) will likely be less than the baseline system leading to a lower required thrust. A lower required thrust means that the entire propulsion system size and thus weight is reduced. So even if the thrust to weight of the aft BLI fan is less than the baseline turbofan, the propulsion system weight of an optimized STARC-ABL aircraft system could still end up less than that of the baseline system. 
Table 7: Comparison of the sized N3CC and STARC-ABL concepts.

\begin{tabular}{lcccc}
\hline \hline Parameter & Units & N3CC & STARC-ABL & \% Change \\
\hline TOGW & $\mathrm{lb}$ & 129,260 & 133,370 & $3.2 \%$ \\
OEW & $\mathrm{lb}$ & 73,690 & 80,480 & $9.2 \%$ \\
Wing Area & $\mathrm{ft}^{2}$ & 1,220 & 1,680 & $37.7 \%$ \\
Thrust (total, SLS) & $\mathrm{lb}$ & 41,020 & 35,280 & $-14.0 \%$ \\
$\mathrm{AR}$ & - & 11.02 & 8.29 & $-24.8 \%$ \\
SOC C $L$ & - & 0.59 & 0.45 & $-23.7 \%$ \\
L/D @ SOC C & - & 21.4 & 22.3 & $4.2 \%$ \\
SOC TSFC & $\mathrm{lb} / \mathrm{hr} / \mathrm{lb}$ & 0.437 & 0.373 & $\mathbf{- 1 4 . 6} \%$ \\
$900 \mathrm{~nm} \mathrm{Block} \mathrm{Fuel/seat}$ & $\mathrm{lb} / \mathrm{seat}$ & 39.53 & 36.86 & $\mathbf{- 6 . 8 \%}$ \\
$3500 \mathrm{~nm}$ Block Fuel & $\mathrm{lb}$ & 22,050 & 19,350 & $\mathbf{- 1 2 . 2 \%}$ \\
\hline \hline
\end{tabular}

\section{Results and Discussion}

Table 7 compares the sized STARC-ABL concept to the N3CC concept. The first item of note is the significant TSFC improvement and fuel burn reduction on both the economic mission and design mission ranges. The turboelectric propulsion architecture resulted in nearly a $15 \%$ improvement in TSFC at the start of cruise condition. This translates into $7 \%$ and $12 \%$ block fuel burn savings for the economic and design missions, respectively. This was despite an OEW and TOGW increase from the N3CC configuration due to the larger wing and empennage surfaces. The SLS thrust of the engines were able to be reduced due to the addition of the rear fuselage BLI fan, an extremely efficient thrust producing device due to the ingested boundary layer and the lack of power lapse with altitude.

A key benefit that was captured in this analysis was the reduced turbofan size and weight. This resulted from the lack of power lapse as a function of altitude in the electric motor, and the increase in propulsive efficiency of the aft-fan allowing the underwing turbofans to be downsized. As the fan diameter was decreased, the turbofan system weights, including the nacelle, decreased dramatically. This reduction in turbofan weight offsets the additional component weights for the turboelectric system, resulting in a net propulsion system weight reduction. As noted in the previous discussion of the weight savings of the STARC-ABL propulsion system, more detailed analysis is necessary before concluding that the turboelectric system is conclusively lighter. The decrease in turbofan size also provided a wetted area reduction for the nacelle, which resulted in an additional viscous drag benefit.

Not all of the potential benefits of the STARC-ABL concept were captured in the analysis. One benefit of BLI not captured in this analysis is a reduction in total wake dissipation. Although only a secondary effect when compared to the propulsive efficiency increase due to BLI, ${ }^{16}$ inclusion of this effect would improve the overall system fuel burn benefit. As mentioned previously, no aerodynamic shaping of rear fuselage and nacelle was performed. It is possible that the fuselage shape leading toward the rear nacelle, and the nacelle outer mold line, could be shaped to provide a static pressure field that would result in a forward axial force, or thrust. Finally, an electrical rather than mechanical connection of the turbine and aft-fan, combined with the ability of electrical machines to independently vary the torque and speed, allows the motor and generator to shift the operating line of the genFan fan, LPC, LPT, and the aft-fan. Also, the ratio of the genFan fan shaft speed to the aft-fan shaft speed can be varied during operation allowing each system to operate at its own optimal operating point. This has the potential to allow increase turbomachinery efficiency and operability at off-design conditions. It is believed that these unmodeled benefits would offset (whether fully or not is unknown) the system penalties associated with a thermal management system, maintaining a total system fuel burn benefit for the STARC-ABL concept.

\section{A. Design Space Exploration}

The STARC-ABL and N3CC concepts were similar in gross weight, approximately 4,000 pounds difference, but their wing geometries are quite different. Reviewing Table 7, the wing area of the STARC-ABL is significantly larger than the $\mathrm{N} 3 \mathrm{CC}$ at 1,680 square feet compared to 1,220 square feet. The increase in wing 


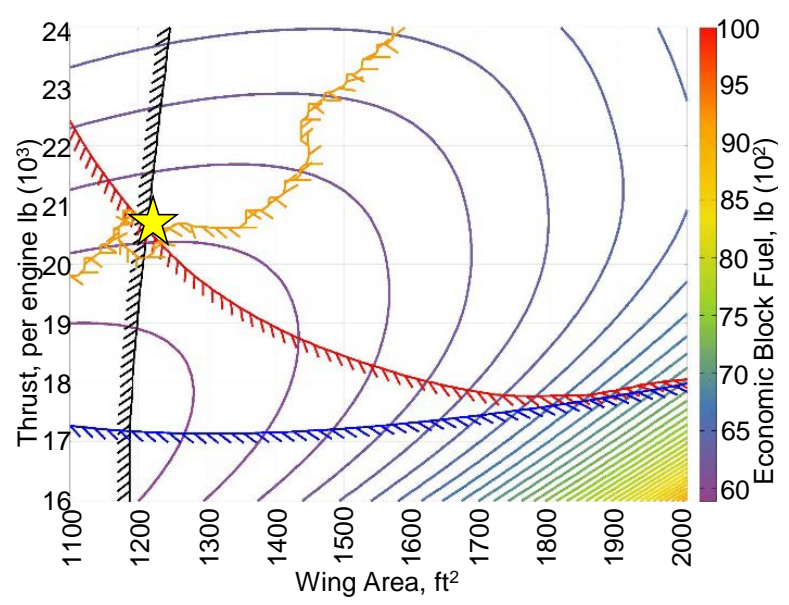

(a) N3CC design space.

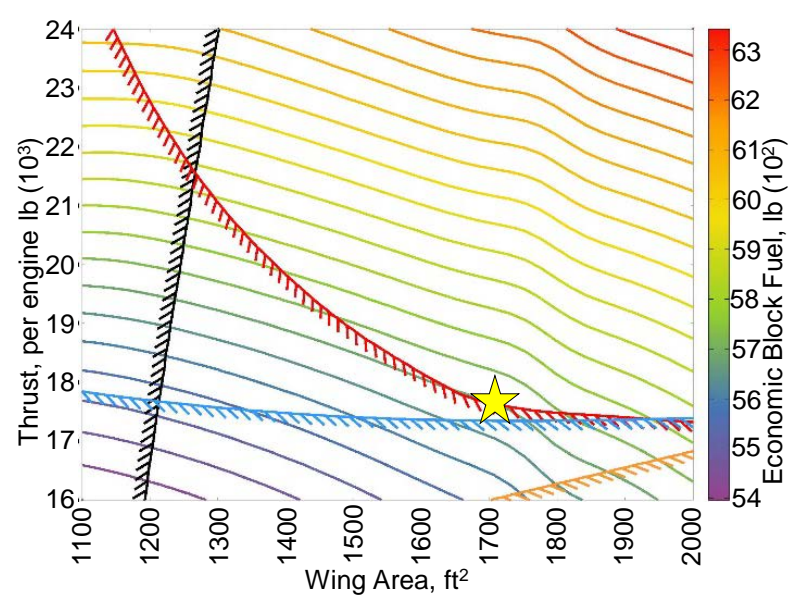

(b) STARC-ADL design space.

Figure 8: Design space of the N3CC (Fig. 8a) and the STARC-ABL (Fig. 8b) with the contours showing the economic mission block fuel burn as functions of wing area and static thrust. The optimized configurations highlighted are by the star. Constraints lines include the balance field length (red), approach velocity (black), initial cruise altitude capability (orange), and second segment climb thrust requirement (blue).

area resulted in an aspect ratio decrease for the STARC-ABL due to the imposed span constraint. Throughout the development of the STARC-ABL concept, several optimizations were run using Design Explorer that consistently resulted in a wing area increase. Design Explorer is an excellent optimizer that is capable of finding an optimum solution in a noisy and discontinuous design space. However, due to the methods used in the Design Explorer optimizer it is difficult to perceive design space shape. As such, it was desired to gain better insight as to why the addition of the turboelectric propulsion architecture consistently caused the STARC-ABL wing area to increase nearly $40 \%$.

To visualize the design space, a matrix of 1500 designs were run for both the N3CC and STARC-ABL concepts varying wing area from 1100 to 2000 square feet and sea level static thrust per engine from 16,000 to 24,000 pounds. Figure 8 shows the result of this design space exploration. The contour plots were generated using a large data visualization software called Rave, ${ }^{17}$ a tool developed in the Aerospace Systems Design Laboratory at Georgia Tech ${ }^{\mathrm{c}}$. Clearly shown in Fig. 8 is the drastically different color contour shape indicating the economic mission block fuel burn. The yellow star on each of the plots shows the optimized result from the Design Explorer optimizer. Four constraint lines are drawn in Fig. 8a and Fig. 8b showing the minimum performance requirements of FAR Part 25 takeoff field length (red, must be less than 8,190 feet), second segment climb performance (blue, must have sufficient thrust to maintain the minimum required gradient with a single engine), approach velocity (black, must be less than 140 knots), and ICAC (orange, must have sufficient thrust to climb higher than the optimal starting cruise altitude). Each data point in the contour plots was discrete, and therefore it should be noted that the constraint lines are representative and have been smoothed for clarity (the one exception being the ICAC constraint line in Fig. 8a).

It is clear that changing from the conventional propulsion system of the $\mathrm{N} 3 \mathrm{CC}$ concept to the turboelectric propulsion system of the STARC-ABL drastically changes the shape of the design space. The shape of the economic block fuel burn contours changes from being equally sensitive to thrust and wing area (Fig. 8a) to being mostly sensitive to SLS thrust (Fig. 8b). The other major design space change was the relief of the ICAC constraint, which allowed the required SLS thrust to be decreased providing a significant fuel burn benefit. For the N3CC, approach velocity, ICAC, and takeoff field length were all active constraints on the design, whereas for the STARC-ABL only takeoff field length was active with the contours driving the optimal design location on the curve in the thrust/wing area designs space.

${ }^{\mathrm{c}}$ http: //www.rave.gatech.edu/index.shtml 


\section{B. System Sensitivities}

A nominal turboelectric architecture was designed using a set of conservative simplifying assumptions. The simplifying assumptions were made to enable a rapid analysis of the STARC-ABL concept, and to provide a set of baseline assumptions for component $\mathrm{N}+3$ technology advancements. Due to the uncertainty in some of the technology assumptions, it was desired to know the sensitivity of the predicted performance to these assumptions. An understanding of the system performance to the assumptions also provides guidance for future technology development.

Total propulsion system weight and TSFC sensitivities to three input variables were explored for the turboelectric architecture, the aft-fan design motor power, the aft-fan FPR, and the total electrical system efficiency. The TSFC and total propulsion system weight sensitivities are shown for the top of climb condition in Figs. 9 and 10. The vertical axes are dimensional, and the horizontal axes are normalized as a percent change from the nominally assumed values of the baseline turboelectric system: 3500 horsepower, a FPR of 1.25 , and a total electrical efficiency of $90 \%$. The conventional turbofan with $\mathrm{N}+3$ performance assumptions is shown as a constant orange line.
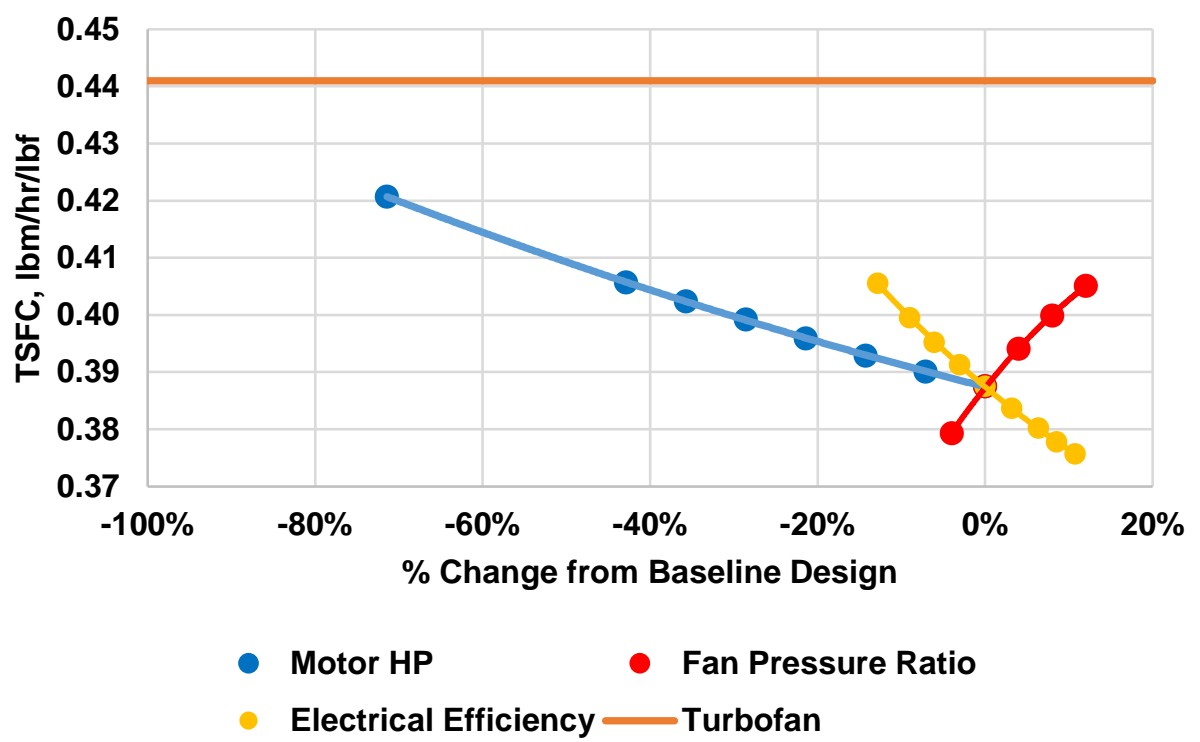

Figure 9: Sensitivity of TSFC at the top of climb (TOC) condition to the rear propulsor motor HP, BLI fan pressure ratio, and system total electrical efficiency. Baseline values for the horizontal axis normalization are $3,500 \mathrm{hp}, 1.25$, and $90 \%$ respectively.

As shown in Fig. 9 the electrical system efficiency and aft-fan FPR have the greatest impact on TSFC, but the motor horsepower sensitivity was also significant. Increasing the motor size beyond the 3500 horsepower would improve the TSFC, but at the expense of motor volumetric size and weight to the point of being prohibitive. The farthest right data point on the electrical efficiency line corresponds to a $100 \%$ efficient electrical system, and is therefore an upper limit on the benefit of super-efficient electrical components. The left most data point on the electrical efficiency line corresponds to a total electrical transmission efficiency of $77 \%$. Even with this very low efficiency the TSFC was still $8 \%$ less than the baseline system. Despite the large sensitivities to the motor design horsepower, electrical efficiency, and FPR, all the data points show that the turboelectric system resulted in a TSFC better than a conventional propulsion system.

The trends for the propulsion system weight (Fig. 10) versus the design motor horsepower aft-fan FPR are different than for the TSFC. The design motor horsepower trend has a parabolic shape with a minimum occurring at the $-20 \%$ mark, which corresponds to a motor horsepower of approximately 2800 . Despite the global parabolic trend, the propulsion system weight sensitivity was quite small between $0 \%$ and $-35 \%$, but resulted in a significant change in TSFC. Increasing the rear BLI FPR decreased the total propulsion system weight as the size of the fan was decreased, and increasing the electrical efficiency decreased the propulsion system weight as would be expected. It should be noted that the total electrical system efficiency would have to be reduced to $59 \%$ and $54 \%$ before the TSFC and propulsion system weight, respectively, would equal the turbofan system. This implies that having a cryogenic cooling system to enable superconducting 
electrical components is unnecessary for the success of the STARC-ABL concept.
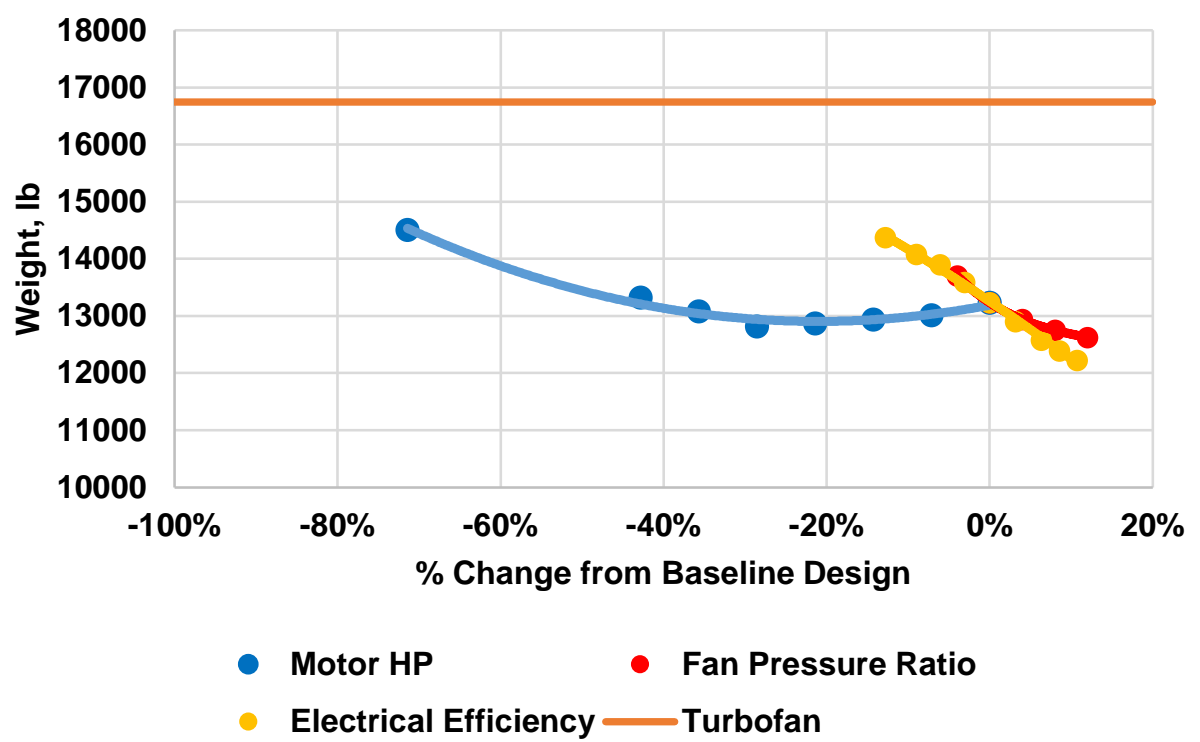

Figure 10: Sensitivity of the total propulsion system weight to design motor horsepower, rear BLI fan pressure ratio, and total electrical system efficiency. Baseline values for the horizontal axis normalization are $3,500 \mathrm{hp}, 1.25$, and $90 \%$ respectively.

\section{Conclusions}

An $\mathrm{N}+3$ single-aisle class commercial transport concept was developed that employs a turboelectric propulsion system architecture. The propulsion system architecture consists of two underwing turbofans with generators extracting power from the fan shaft and transmitting it to a rear fuselage, axisymmetric boundary layer ingesting fan. The single-aisle turboelectric aircraft with an aft boundary layer propulsor (STARC-ABL) represents one of the most basic uses of the turboelectric architecture, but was a solid starting point to gain understanding on how the turboelectric architecture changes the design space. For a point of comparison, an $\mathrm{N}+3$ conventional configuration (N3CC) model was also developed to be representative of a 737-800like aircraft in the 2035 timeframe.

Results indicate that a significant fuel burn benefit can be obtained with the turboelectric architecture using conservative technology assumptions, especially conventional electrical components with moderate efficiencies. The STARC-ABL has a $7 \%$ block fuel burn reduction for the economic mission, and $12 \%$ block fuel burn reduction for the design mission. Key sources of this benefit are the increase in propulsion system efficiency from the rear fuselage BLI fan that ingests only a portion of the boundary layer, and the downsizing of the underwing turbofans, which helps offset the weight of the additional turboelectric system components.

A matrix of thrust and wing area inputs were analyzed to visualize the design space and gain insight as to how the turboelectric propulsion system changes the shape of the design space. From this visualization it became clear that the economic block fuel contours changed from being equally sensitive to thrust and wing area for the N3CC to the STARC-ABL mostly being sensitive to thrust. The ICAC constraint was also alleviated in the STARC-ABL concept allowing the economic block fuel contours and takeoff field length requirements to drive the optimal design.

Finally, a sensitivity analysis was run to better understand the relationship of the system benefits to some of the turboelectric system design assumptions, and to indicate the technology levels required to make the STARC-ABL concept viable, providing a technology development road map. It was found that TSFC was sensitive to the selected aft-fan motor horsepower, aft-fan FPR, and total electrical system efficiency, but all designs explored still had a TSFC better than the conventional $\mathrm{N}+3$ turbofan. The total propulsion system weight was also found to be sensitive to FPR and the electrical system efficiency, but was fairly insensitive to rear motor horsepower over a broad range of horsepower (from 2275 to 3500 horsepower). The propulsion system weights do contain some uncertainty due to the modeling methods used and require 
additional scrutiny, but the trend of the turbofan weight reduction offsetting some or all of the turboelectric components should remain.

Overall, this research has shown that the STARC-ABL concept may be a good first candidate for a turboelectric propulsion system architecture that provides significant fuel burn benefits when compared to a similar technology conventional configuration.

\section{Acknowledgments}

This work was completed with support from the Systems Analysis and Integration group under the Advanced Air Transport Technology (AATT) project in the Advanced Air Vehicles Program. The authors would like to thank Bill Haller (NASA Glenn Research Center), Mark Guynn (NASA Langley Research Center), and Chris Droney (Boeing Research and Technology) for their support of this research.

\section{References}

1 "707/720 Commercial Transport: Historical Snapshot," 2015, http://www.boeing.com/history/ products $/ 707$. page.

${ }^{2}$ Bradley, M. K., Droney, C. K., Paisley, D., Roth, B., Gowda, S., and Kirby, M., "SUGAR Phase 1 Final Review," April 2010, http://aviationweek.typepad.com/files/boeing_sugar_phase_i_final_ review_v5.pdf.

${ }^{3}$ Bradley, M. K. and Droney, C. K., "Subsonic Ultra Green Aircraft Research: Phase I Final Report," Contractor Report NASA/CR-2011-216847, NASA Langley Research Center, Hampton, VA, April 2011.

${ }^{4}$ Bradley, M. K. and Droney, C. K., "Subsonic Ultra Green Aircraft Research: Phase II: N+4 Advanced Concept Development," Contractor Report NASA/CR-2012-217556, NASA Langley Research Center, Hampton, VA, May 2012.

${ }^{5}$ Bradley, M. K., Droney, C. K., and Allen, T., "Boeing N+3 SUGAR: Final Update Presentation," (Unpublished).

${ }^{6}$ Bradley, M. K., Droney, C. K., and Allen, T. J., "Subsonic Ultra Green Aircraft Research Phase II: Truss Braced Wing Design Exploration," Contractor Report NASA/CR-2015-218704/Volume I, NASA Langley Research Center, Hampton, VA, April 2015.

${ }^{7}$ Bradley, M. K. and Droney, C. K., "Subsonic Ultra Green Aircraft Research Phase II: Hybrid Electric Design Exploration," Contractor Report NASA/CR-2015-218704/Volume II, NASA Langley Research Center, Hampton, VA, April 2015.

${ }^{8}$ NASA Procedural Requirements 7123.1B, NASA Systems Engineering Processes and Requirements, Appendix J: Technology Readiness Levels, April 2013.

${ }^{9}$ Hahn, A. S., "Vehicle Sketch Pad: A Parametric Geometry Modeler for Conceptual Aircraft Design," 48th AIAA Aerospace Sciences Meeting, American Insittue of Aeronautics and Astronautics, Orlando, FL, 2010, pp. 1 - 11, AIAA-2010-0657.

${ }^{10}$ Hahn, A. S., "Vehicle Sketch Pad Aircraft Modeling Strategies," 61st AIAA Aerospace Sciences Meeting, American Insittue of Aeronautics and Astronautics, Grapevine, TX, 2013, pp. 1 - 9, AIAA-2013-0331.

${ }^{11}$ Morris, J. and Ashford, D., "Fuselage Configuration Studies," SAE Technical Paper 670370, Society of Automotive Engineers, 1967.

${ }^{12}$ McCullers, L., "Aircraft Configuration Optimization Including Optimized Flight Profiles," Tech. Rep. NASA CP-2327, NASA, 1984.

${ }^{13}$ Feagin, R. C. and Morrison, W. D., "Delta Method, An Empirical Drag Buildup Technique," Contractor Report NASA/CR-151971, Lockheed-California Co., Burbank, CA, December 1978. 
${ }^{14}$ Tong, M. and Naylor, B., "An Object-Oriented Computer Code for Aircraft Engine Weight Estimation," Tech. Rep. NASA/TM-2009-215656, NASA Glenn Research Center, 2009.

${ }^{15}$ Welge, H. R. et al., "N+2 Supersonic Concept Development and Systems Integration," Contractor Report NASA/CR-2010-216842, NASA Langley Research Center, Hampton, VA, August 2010.

${ }^{16}$ Uranga, A., Drela, M., and Greitzer, E., "Power Balance Assessment of BLI Benefits for Civil Aircraft," SciTech 2015, January 2015, (Oral Presentation).

${ }^{17}$ Daskilewicz, M. J. and German, B. J., "RAVE: A Graphically Driven Framework for Agile Design-Decision Support," 13th AIAA/ISSMO Multidisciplinary Analysis Optimization Conference, American Institue of Aeronautics and Astronautics, Fort Worth, TX, 2010, AIAA-2012-3993. 